\title{
Estimativa de parâmetros indicadores de qualidade de carvão a partir de perfilagem geofísica
}

\author{
(Estimation of coal quality indicators using \\ borehole logging data)
}

\section{Resumo}

A qualidade do carvão é, geralmente, estimada através da análise de testemunhos obtidos em furos de sondagem com recuperação, que são custosos e consomem tempo. Perfilagem geofísica fornece uma medida indireta da qualidade do carvão inferida de algumas propriedades físicas lidas pela sonda. De todos os métodos de perfilagem geofísica, a medida de radiação retroespalhada (gama-gama) é apropriada para identificar a camada de carvão e inferir qualidade ao mesmo. Esse trabalho estuda a possível correlação entre a radiação retroespalhada e o teor de cinzas. Com os valores obtidos com a perfilagem geofísica e os teores de cinzas obtidos para os mesmos intervalos, foi possível construir um gráfico de correlação e ajustar uma função. A função apresentou um alto coeficiente de correlação e um aceitável erro de estimativa auxiliando, na obtenção de informação a curto prazo com baixo custo e rapidez.

Eng. de Minas, M.Sc, UFRGS

E-mail:twebberbr@yahoo.com.br

\section{Paulo Salvadoretti}

Eng.de Minas, Professor, Dr., DEMIN, UFRGS E-mail: paulo.salvadoretti@ufrgs.br

\section{Jair Carlos Koppe}

Eng. de Minas, Professor, Dr., DEMIN, UFRGS

E-mail: jkoppe@ufrgs.br

\section{João Felipe Coimba Leite} Costa

Eng. de Minas, Professor, Dr., DEMIN, UFRGS

E-mail: jfelipe@ufrgs.br

Palavras-chave: Carvão, perfilagem, qualidade.

\section{Abstract}

Coal quality is commonly analyzed using cores obtained from diamond drill holes, which are costly and time consuming. Geophysical logging provides an indirect measurement of coal quality derived from some physical properties logged by the probe. Among the geophysical logging methods, gamma back scattering (gamma-gamma) is appropriate for identifying coal seams and for inferring some coal quality parameters. This study identifies the possible correlation between gamma-gamma readings and ash content. By using the logged geophysical survey values plotted against the ash content, analyzed at the same intervals, a scatter plot was constructed and a model adjusted. The derived model showed a high correlation coefficient and acceptable estimation error, recommending this practice for obtaining quick, low-cost information for mine planning.

Keyword: Coal, borehole logging, quality. 


\section{Introdução}

A qualidade do carvão mineral é estimada de acordo com certos parâmetros físico-químicos como massa específica, poder calorífico, teores de cinzas e enxofre e matéria volátil. Geralmente, a obtenção dos valores desses parâmetros é conseguida mediante a análise laboratorial de amostras obtidas por sondagem com recuperação de testemunhos. Essa metodologia de aquisição de informações é bastante confiável, porém o custo das sondagens é bastante elevado, uma vez que o planejamento de curto prazo e o controle de teores de lavra requerem um alto número de amostras. Outro revés desse método de amostragem é a chance de ocorrerem baixas recuperações de material de sondagem (testemunhos), impossibilitando a aquisição de amostras para análise.

A perfilagem geofísica é um método de amostragem indireta muito eficaz para medições de grandezas físicas. Com baixo custo de operação e versatilidade no manuseio, a perfilagem geofísica pode ser realizada, concomitantemente, com as operações de lavra, proporcionando resposta imediata do parâmetro medido. Basicamente, a perfilagem geofísica é executada em furos de sondagem ou poços, sejam eles feitos destrutivamente ou com recuperação de material. A ferramenta de perfilagem (geralmente lon- gas hastes metálicas) é inserida no furo e começa a percorrer o mesmo. Durante essa movimentação, são feitas as medidas dos parâmetros de interesse (Figura 1), que são apresentadas em forma de gráficos (perfís geofísicos). Entre as diversas ferramentas disponíveis na perfilagem geofísica, a mais indicada para uso em carvão é conhecida por perfil gamagama ou gama retroespalhado.

Experiências mostraram que para se direcionar um feixe de radiação gama para um corpo-de-prova com massa específica superior á $1 \mathrm{~g} / \mathrm{cm}^{3}$, certas interações ocorrem entre a radiação e os elétrons presentes no material. Devido a essas interações, uma parcela da radiação gama incidente é absorvida pelo material e outra é ricochetada para fora do corpo (retroespalhada). A taxa de radiação retroespalhada está relacionada como a massa específica do material, pois a interação do feixe ocorreu com os elétrons e sabe-se que a quantidade de elétrons de um corpo é proporcional a sua massa específica. $\mathrm{O}$ fenômeno da interação entre radiação gama e elétrons obedece às mesmas leis que regem o decaimento radioativo, logo a relação entre massa específica e taxas de radiação retroespalhada apresenta um comportamento semelhante a uma função exponencial negativa $\left(y=a \cdot e^{-b . x}\right)$. Portanto, conforme a massa específica de um material aumenta, partindo de $1 \mathrm{~g} / \mathrm{cm}^{3}$, as taxas de radi- ação retroespalhada devem diminuir exponencialmente (Figura 2).

A unidade CPS (contagens por segundo) apresentada na Figura 2 é muito usada em perfilagem geofísica para representar as taxas de radiação retroespalhada, que representam uma desintegração a cada segundo.

A massa específica do carvão está relacionada com o seu teor de cinzas, pois, quanto maior o teor de cinzas no carvão, maior a sua massa específica e, conseqüentemente, menor a sua qualidade, reduzindo o seu poder calorífico. Portanto é possível relacionar, diretamente, as taxas de radiação retroespalhada, obtidas através de um perfil geofísico, com teor de cinzas e poder calorífico. A Figura 3 mostra um resumo das relações entre os parâmetros de interesse.

\section{Metodologia}

Esse trabalho se iniciou com uma campanha de sondagens com recuperação de testemunhos. Foram realizados quatro furos de diâmetro $\mathrm{ZW}(16 \mathrm{~cm}) \mathrm{e}$ com o material recuperado foi feita a descrição das colunas litológicas e o material carbonoso foi separado e destinado à analise química para determinação da massa específica e do teor de cinzas. Os furos foram denominados CRZ01, CRZ-02, CRZ-03 e CRZ-04.

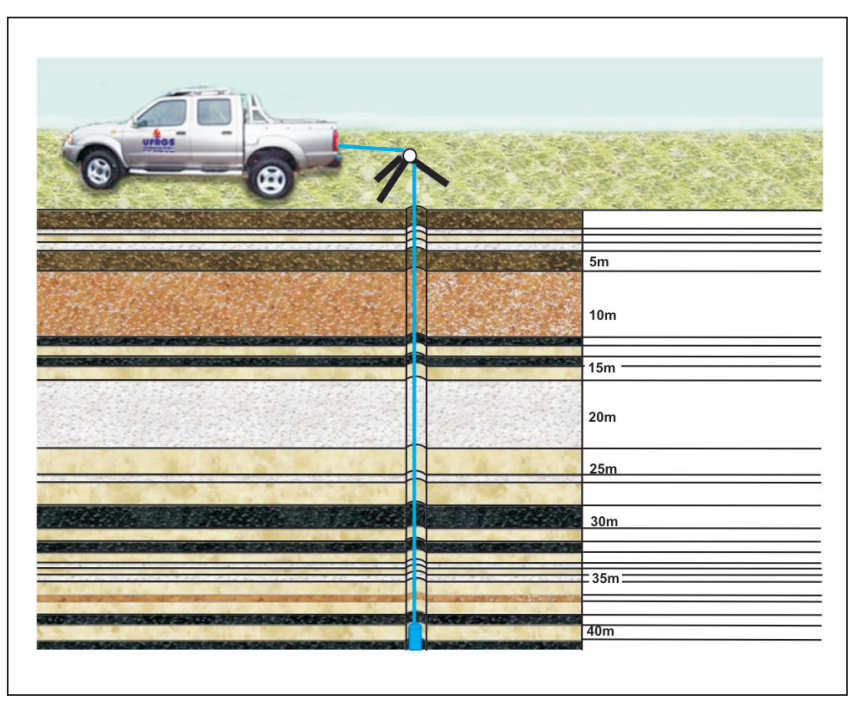

Figura 1 - Execução da perfilagem geofísica de poço (Oliveira, 2005).

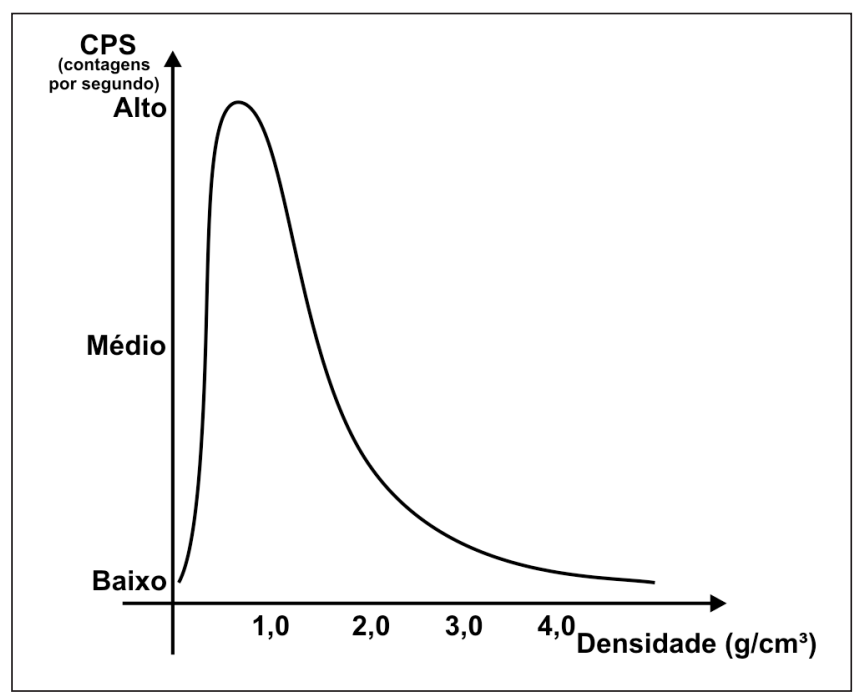

Figura 2 - Relação entre massa específica e radiação retroespalhada (Hoffmann et al., 1982). 
A campanha de perfilagem geofísica foi feita com a sonda de nome SWDS (Sidewall Density Sonde), que mede as taxas de radiação retroespalhada, emissão de radiação gama natural e diâmetro do furo. $O$ feixe de radiação incidente é proveniente de uma fonte de Césio 137, que é preso na extremidade inferior da ferramenta, e a captação da radiação retroespalhada é feita por cintilômetros distribuídos ao longo da referida ferramenta (Figura 4).

Conforme a Figura 4, existe um isolamento (geralmente feito de Chumbo) entre a fonte radioativa e o cintilômetro, para evitar que o mesmo capte raios gama que não sofreram interações com a matéria.

Na Figura 5, observa-se um exemplo de um perfil geofísico obtido com a sonda SWDS.

A imagem mostrada na Figura 5 pode ser dividida em duas partes. $\mathrm{Na}$ coluna da esquerda, temos duas linhas, a de cor vermelha é o perfil de gama natural e a de cor verde é o comportamento da parede do furo ou o diâmetro do mesmo. Na coluna da direita, temos a medida de radiação retroespalhada pelos três cintilômetros presentes na ferramenta, a linha vermelha é o LSD (distante $31 \mathrm{~cm}$ da fonte radioativa), a azul, o HRD (afastado $26 \mathrm{~cm}$ ) e a linha verde é o sinal do $\mathrm{BRD}$ (14 cm de afastamento).

Para realizar esse trabalho, foi escolhido o sinal registrado pelo cintilômetro LSD, que, por ser aquele que está mais afastado da fonte, apresenta valores mais constantes com o tempo de coleta, isto é, em trechos do perfil que acusam carvão (alta taxa de radiação retroespalhada) não teremos valores extremos causados por materiais estranhos presentes na camada de carvão (como pirita), que podem afetar o cálculo da média de raios retroespalhados para a devida camada de carvão.

Tendo em mãos as análises químicas, a descrição geológica dos furos e os perfis geofísicos, foi possível correlacionar a massa específica e a cinza das camadas e ajustar a função que correlaciona a massa específica com as taxas de radiação gama retroespalhada.

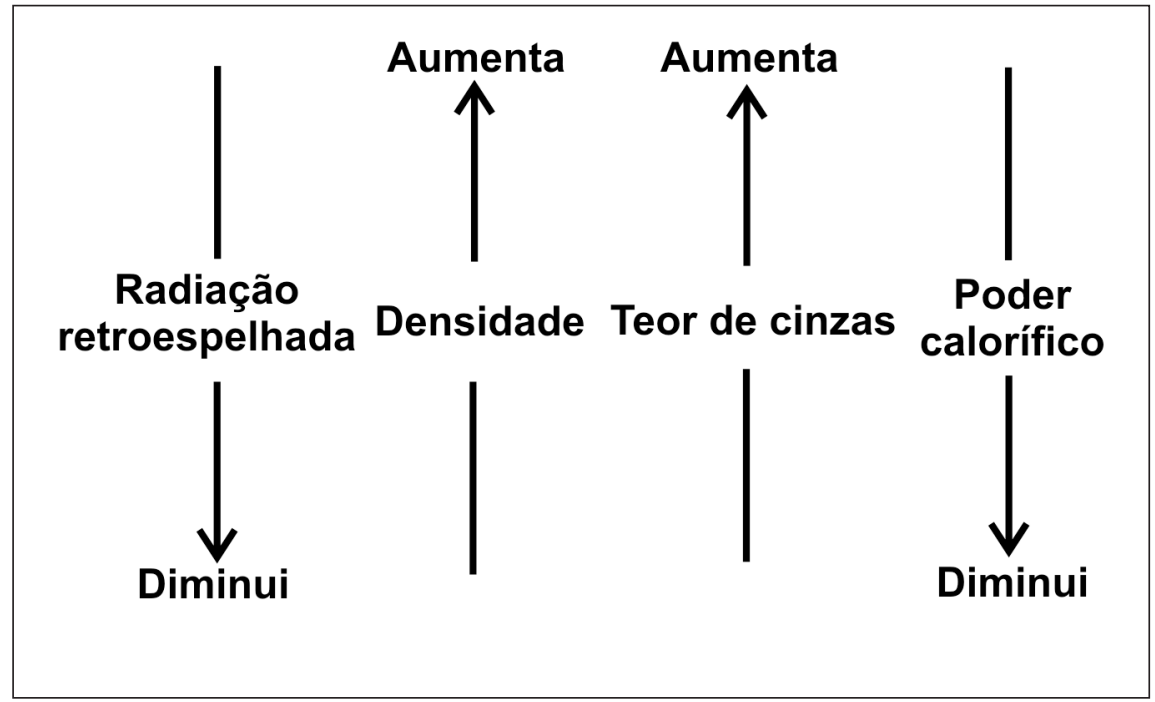

Figura 3 - Relação entre os parâmetros de interesse.

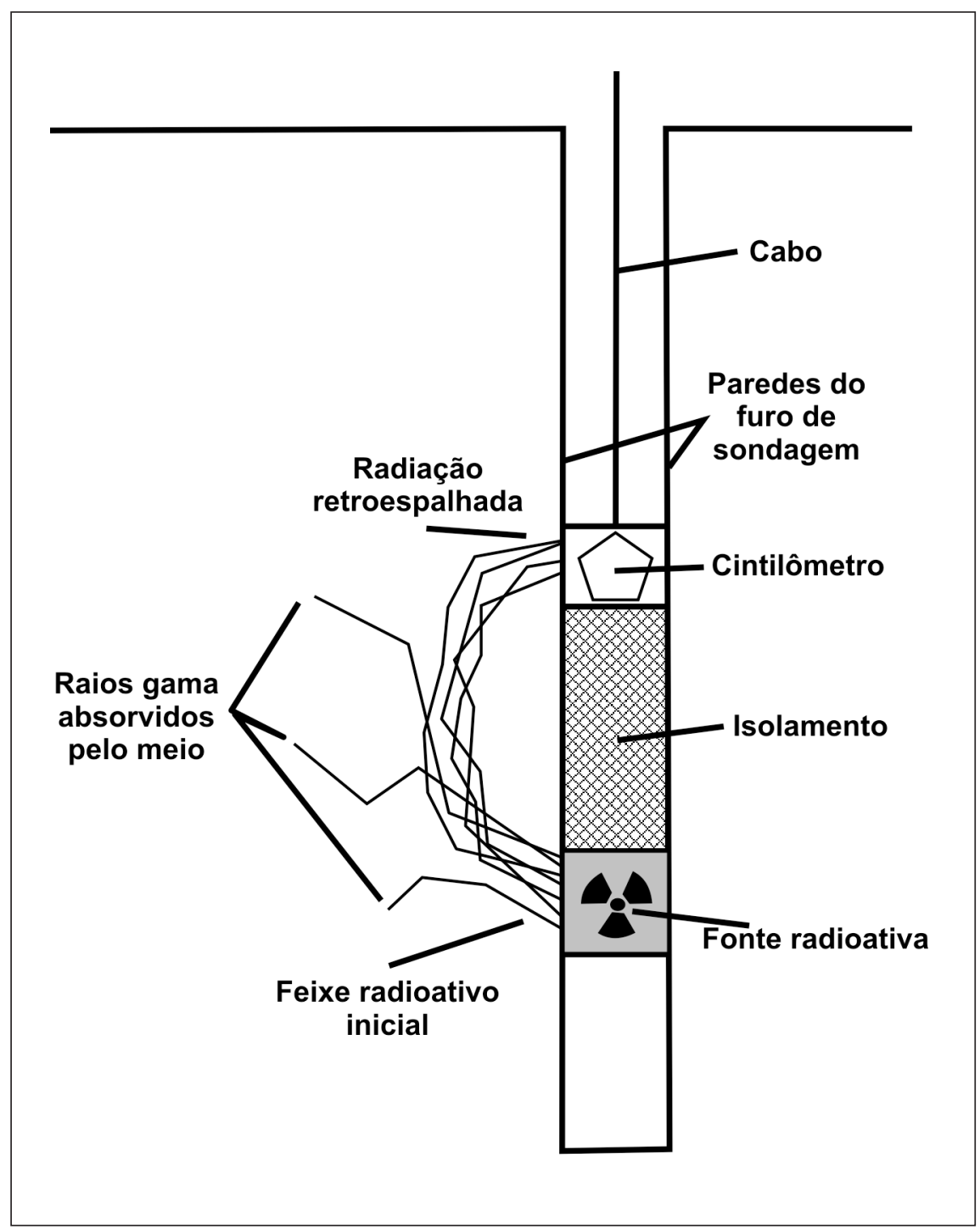

Figura 4 - Princípio da perfilagem de radiação retroespalhada. 
O procedimento de ajuste se iniciou com a conciliação entre os dados geofísicos e a informação da sondagem convencional. Na Figura 6, temos a coluna litológica de um furo ao lado do seu respectivo perfil geofísico, já com as camadas de carvão em destaque.

Para cada intervalo de perfil geofísico, que indica uma camada de carvão, foi calculada a média das radiações retroespalhadas, pois a análise laboratorial dos testemunhos estimou a média da massa específica e do teor de cinzas para cada camada de carvão. A Tabela 1 mostra os resultados de laboratório e de perfilagem geofísica para o furo CRZ-01.

Espera-se que o gráfico de dispersão que compara os dados de massa específica e teor de cinzas com as taxas de radiação retroespalhada tenha um comportamento exponencial negativo semelhante àquele apresentado pela Figura 2.

\section{Resultados}

Para comprovar a eficácia do método, os dados foram tratados da seguinte maneira:

i. A informação geofísica e laboratorial dos furos CRZ-03 e CRZ-04 foi utilizada para construir as funções de estimativa de massa específica.

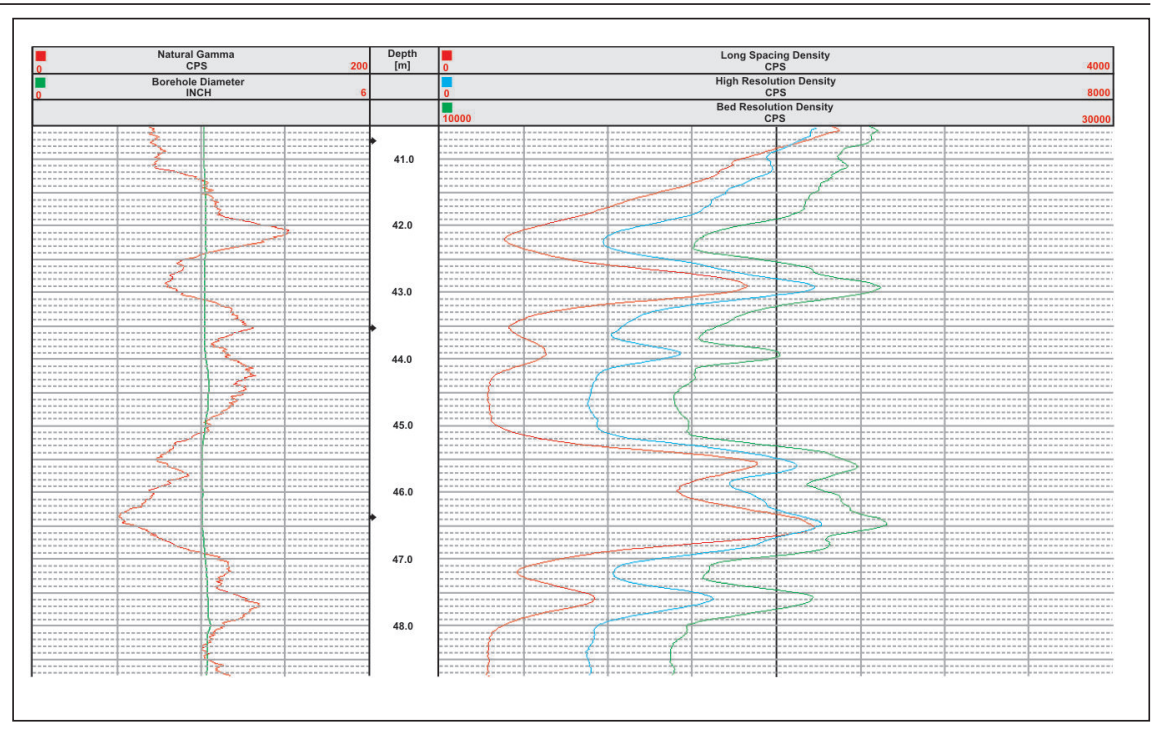

Figura 5 - Exemplo do perfil obtido pela sonda SWDS.

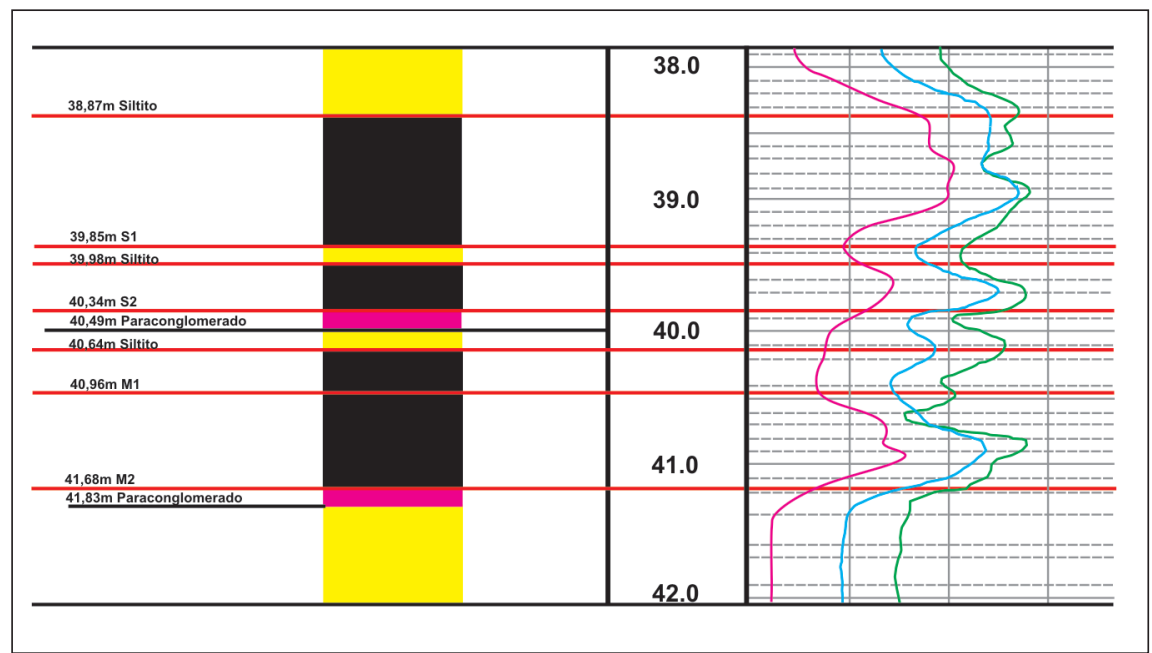

Figura 6 - Conciliação entre o perfil geofísico e a coluna litológica de um furo já com as camadas de carvão em destaque.

Tabela 1 - Resultados de análise de laboratório e perfilagem geofísica para o furo CRZ-01.

\begin{tabular}{c|c|c|c|c|c|c}
\hline Furo & Camada & De $(\mathbf{m})$ & Até $(\mathbf{m})$ & Massa específica $\left(\mathbf{g} / \mathbf{c m}^{3}\right)$ & Cinza $(\%)$ & LSD média (CPS) \\
\hline CRZ-01 & S1 & 13,91 & 14,22 & 1,73 & 45,92 & 2584 \\
\hline CRZ-01 & M1 & 24,25 & 24,85 & 1,77 & 46,99 & 1970 \\
\hline CRZ-01 & I1 & 45,75 & 46,25 & 1,81 & 55,28 & 1732 \\
\hline CRZ-01 & S2 & 14,89 & 15,00 & 1,82 & 52,09 & 2468 \\
\hline CRZ-01 & M2A & 26,25 & 26,65 & 1,87 & 56,92 & 1836 \\
\hline CRZ-01 & M2B & 27,05 & 27,59 & 1,95 & 59,60 & 1738 \\
\hline CRZ-01 & M3 & 30,98 & 31,13 & 1,97 & 61,08 & 1349 \\
\hline CRZ-01 & I2 & 48,48 & 48,78 & 1,99 & 64,03 & 1232 \\
\hline
\end{tabular}


ii. A função de calibração obtida foi aplicada aos dados geofísicos dos furos CRZ-01 e CRZ-02 para estimativa das massas específicas.

iii. Feita a comparação entre as massa específicas laboratoriais e as massas específicas obtidas pelo ajuste para os furos CRZ-01 e CRZ-02.

Seguindo os passos anteriormente apresentados, o primeiro ajuste realizado foi aquele que inclui os dados geofísicos e de análise de laboratório dos furos CRZ-03 e CRZ-4. O gráfico de dispersão obtido pode ser visto na Figura 7.

Como era esperado, a dispersão mostrada na Figura 7 é semelhante ao comportamento da função exponencial negativa apresentada na Figura 2. Para melhorar o ajuste, foram adicionados mais dois pontos, que foram obtidos em testes de laboratório: uma medida feita em uma cuba com água e outra realizada em um bloco de alumínio. Como se tem conhecimento dos valores das massas específicas desses meios homogêneos $\left(1 \mathrm{~g} / \mathrm{cm}^{3}\right.$ para a água e $2,5 \mathrm{~g} / \mathrm{cm}^{3}$ para o alumínio), a adição deles na dispersão torna o ajuste mais preciso.

A função ajustada sobre a dispersão da Figura 6 foi:

$y=84236,709 * \exp ^{\left(-2,037^{*} x\right)}$

onde $\mathrm{x}$ é a massa específica do meio e y é a taxa de radiação retroespalhada.

Isolando a variável x (massa específica), temos:

$\mathrm{x}=(1 /-2,037) * \ln (\mathrm{y} / 84236,709)$

Com a função anteriormente apresentada, é possível estimar-se massas específicas em função das taxas de radiação retroespalhada. Agora, é possível estimar-se as massas específicas das camadas de carvão presentes nos furos CRZ-01 e CRZ-02, usando a Equação 2 aplicada às taxas de radiação medidas pela perfilagem geofísica executada nesses dois furos.

Para estimativa dos teores de cinzas, foi feito um ajuste sobre a dispersão, que compara as massas específicas e teores de cinzas obtidos em laboratório para os carvões dos furos CRZ-03 e
CRZ-04. Como se sabe, esse dois parâmetros possuem uma relação proporcional, isto é, o aumento no valor de um implica o crescimento do outro, portanto será feito o ajuste de uma função linear sobre o gráfico de dispersão. A Figura 8 trás a dispersão com o ajuste efetuado.
A função ajustada no gráfico da Figura 8 foi:

$y=60,804 \cdot x-58,218$

onde y é o teor de cinzas e $\mathrm{x}$ é a massa específica.

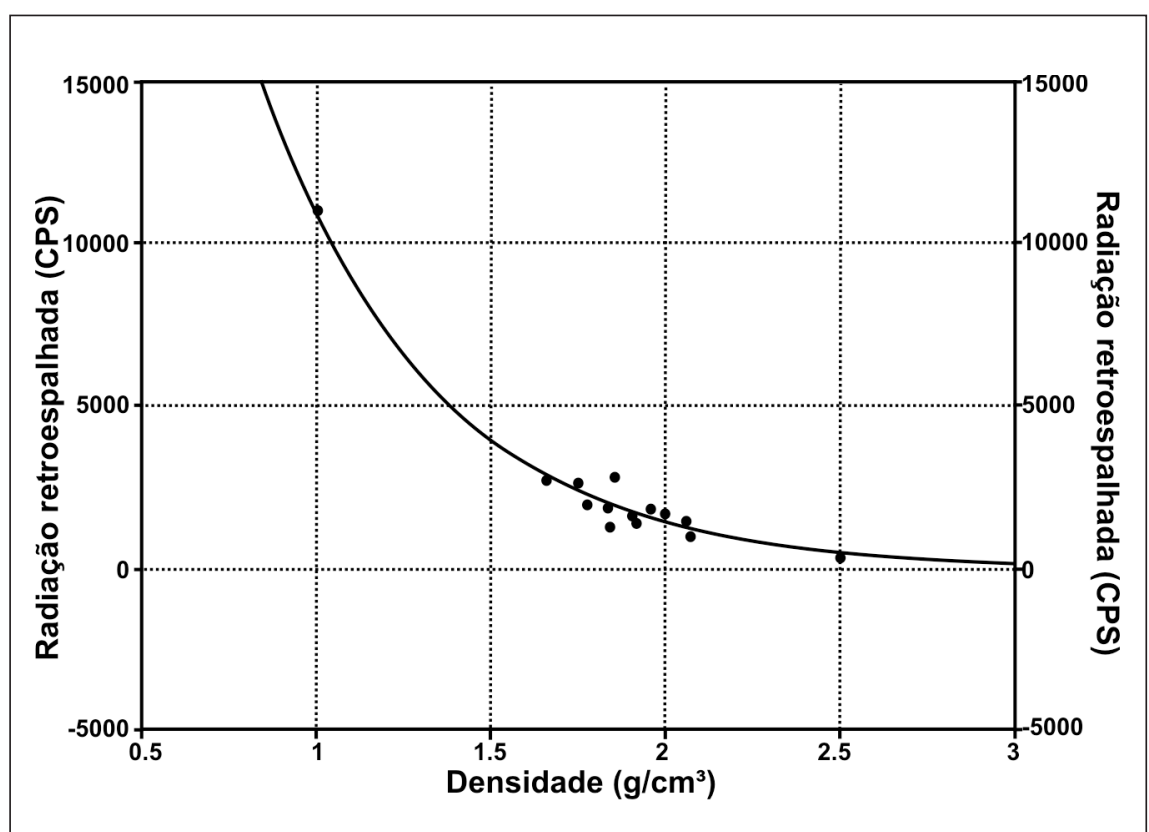

Figura 7 - Gráfico de dispersão com os dados de massa específica de laboratório e radiação retroespalhada dos furos CRZ-03 e CRZ-04.

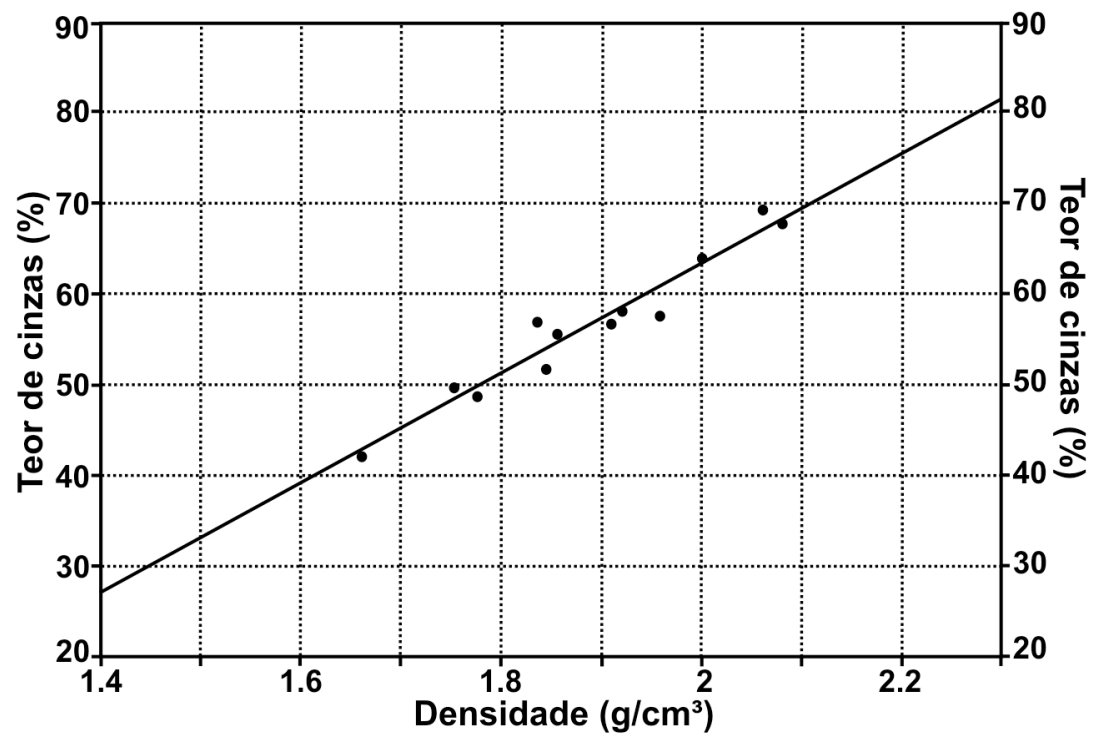

Figura 8 - Gráfico de dispersão entre dados de massa específica e teor de cinzas obtidos em laboratório para os carvões dos furos CRZ-03 e CRZ-04. 
Estimativa de parâmetros indicadores de qualidade de carvão a partir de perfilagem geofísica

Isolando a massa específica na Equação 3, inserindo-a na Equação 2 e efetuando as devidas transformações, obteve-se:

$$
y=-58,218-29,848 \cdot \ln (x / 84236,709)
$$

onde y é o teor de cinzas e x é taxa de radiação retroespalhada.

Com as equações 2 e 4 , foi possível se estimarem massas específicas e teores de cinzas para os carvões dos furos CRZ-01 e CRZ-02, tendo-se, como base, apenas as taxas de radiação retroespalhada medidas pela perfilagem geofísica. Os resultados obtidos podem ser observados na Tabela 2.

De acordo com os valores da Tabela 2, foi obtido um erro absoluto médio, para as estimativas de massa específica igual a $-0,02 \mathrm{~g} / \mathrm{cm}^{3}$, e, para os teores de cinzas, um erro absoluto médio de $-1,73 \%$. Esses valores resultam em um erro porcentual máximo de $-1,14 \%$, para as estimativas de massa específica, e de $-2,8 \%$, para as estimativas de teor de cinzas.

\section{Discussão}

Os resultados mostram que a variação das taxas de raios gama retroespalhados está relacionada com a variação de massa específica das rochas, isto é, altas taxas de raios indicam baixas massas específicas, enquanto que baixas taxas indicam altas massas específicas. Como a massa específica do carvão está intimamente relacionada com o seu teor de cinzas, relacionou-se, diretamente, as taxas de radiação obtidas através de um perfil geofísico com o teor de cinzas encontrado ao analisar o material recuperado do furo de sondagem que foi perfilado. Após, foi modelada a função que relaciona a radiação retroespalhada e teor de cinzas, calibrando o equipamento para obter, diretamente, o perfil do parâmetro escolhido, mesmo em furos destrutivos, isto é, sem recuperação de testemunhos.

Foi observado que os valores para as taxas de raios gama retroespalhados coletados em perfis geofísicos realizados em furos de diâmetro ZW são superiores aos valores obtidos em perfis geofísicos feitos em furos de diâmetro NW

Tabela 2 - Comparação entre as estimativas de massa específica e teor de cinzas para os furos CRZ-01 e CRZ-02.

\begin{tabular}{|c|c|c|c|c|c|c|c|c|c|c|}
\hline Furo & Camada & $\begin{array}{l}\text { Den. } \\
\text { Lab. } \\
\left(\mathbf{g} / \mathbf{c m}^{3}\right)\end{array}$ & $\begin{array}{c}\text { Cz. Lab. } \\
(\%)\end{array}$ & $\begin{array}{l}\text { Rad. } \\
\text { retroespalhada } \\
\text { (CPS) }\end{array}$ & $\begin{array}{l}\text { Den. } \\
\text { Per. } \\
\left(\mathbf{g} / \mathrm{cm}^{3}\right)\end{array}$ & $\begin{array}{c}\text { Erro } \\
\text { Ab. } \\
\left(\mathbf{g} / \mathbf{c m}^{3}\right)\end{array}$ & $\begin{array}{l}\text { Erro } \\
\text { Por. } \\
(\%)\end{array}$ & $\begin{array}{l}\text { Cz. } \\
\text { Per. } \\
(\%)\end{array}$ & $\begin{array}{l}\text { Erro } \\
\text { Ab. } \\
(\%)\end{array}$ & $\begin{array}{l}\text { Erro } \\
\text { Por. } \\
(\%)\end{array}$ \\
\hline \multirow{8}{*}{ CRZ-01 } & S1 & 1,73 & 45,92 & 2584 & 1.71 & -0.02 & -1.28 & 45.78 & -0.14 & -0.30 \\
\hline & S2 & 1,82 & 52,09 & 2468 & 1.73 & -0.09 & -4.77 & 47.15 & -4.94 & -9.48 \\
\hline & M1 & 1,77 & 46,99 & 1970 & 1.84 & 0.08 & 4.40 & 53.89 & 6.90 & 14.68 \\
\hline & $\mathrm{M} 2 \mathrm{~A}$ & 1,87 & 56,92 & 1836 & 1.88 & 0.01 & 0.30 & 55.98 & -0.94 & -1.65 \\
\hline & M2B & 1,95 & 59,6 & 1738 & 1.91 & -0.04 & -2.11 & 57.63 & -1.97 & -3.30 \\
\hline & M3 & 1,97 & 61,08 & 1349 & 2.03 & 0.06 & 2.87 & 65.18 & 4.10 & 6.72 \\
\hline & 11 & 1,81 & 55,28 & 1732 & 1.91 & 0.10 & 5.37 & 57.73 & 2.45 & 4.43 \\
\hline & 12 & 1,99 & 64,03 & 1232 & 2.07 & 0.09 & 4.28 & 67.89 & 3.86 & 6.04 \\
\hline \multirow{8}{*}{ CRZ-02 } & S1 & 1,69 & 44,94 & 2548 & 1.72 & 0.03 & 1.68 & 46.20 & 1.26 & 2.81 \\
\hline & S2 & 1,83 & 54,81 & 2452 & 1.74 & -0.09 & -4.96 & 47.35 & -7.46 & -13.61 \\
\hline & M1 & 1,81 & 49,03 & 2244 & 1.78 & -0.03 & -1.66 & 49.99 & 0.96 & 1.97 \\
\hline & $\mathrm{M} 2 \mathrm{~A}$ & 1,81 & 50,93 & 2585 & 1.71 & -0.10 & -5.36 & 45.78 & -5.15 & -10.12 \\
\hline & M2B & 1,91 & 58,79 & 2449 & 1.74 & -0.18 & -9.19 & 47.39 & -11.40 & -19.39 \\
\hline & M3 & 2,02 & 65,94 & 1892 & 1.86 & -0.15 & -7.60 & 55.08 & -10.86 & -16.47 \\
\hline & 11 & 2,00 & 62,46 & 1481 & 1.98 & -0.01 & -0.71 & 62.39 & -0.06 & -0.10 \\
\hline & 12 & 1,87 & 60,49 & 1822 & 1.88 & 0.01 & 0.48 & 56.21 & -4.28 & -7.07 \\
\hline
\end{tabular}


$(7,6 \mathrm{~cm})$. Isto ocorre devido à maior presença de água entre a sonda e as paredes do furo causada pelo maior diâmetro do furo ZW e, como a água possui uma massa específica igual a $1 \mathrm{t} / \mathrm{m}^{3}$, ela apresenta uma alta taxa de raios retroespalhados, que são captados pelos cintilômetros, amplificando as taxas de raios retroespalhados pelas formações rochosas. Logo as funções ajustadas para inferir os valores de massa específica e cinzas se mostraram eficientes apenas nos perfis efetuados em furos de diâmetro $\mathrm{ZW}(16 \mathrm{~cm})$, pois, ao se perfilar um furo de diâmetro NW foram obtidos valores de massa específica e teor de cinzas incoerentes com as formações litológicas.

Observa-se ser necessário que a calibragem seja feita sempre para um diâmetro específico de sondagem e que a mudança no diâmetro implica, necessariamente foram um novo processo de ajuste de função.

\section{Conclusões}

Os resultados são bastante promissores e viabilizam o uso da perfilagem geofísica para inferência de parâmetros indicadores de qualidade de carvão mineral. Mostrou-se um método versátil e de baixo custo, que diminui, consideravelmente, o custo para amostragem e análise de informações de curto prazo. Adicionalmente, os furos destrutivos (de desmonte, por exemplo) passaram a ser perfilados e sua informação integrada aos demais dados via co-krigagem para estimativa do parâmetro de interesse.

Um dos trabalhos futuros é modelar novas funções que se adaptem a diferentes diâmetros de furos.

\section{Agradecimentos}

À CAPES pelo auxilio financeiro e à Copelmi Mineração Ltda pelo fornecimento de importantes informações.

\section{Referências bibliográficas}

HOFFMAN, G.L., JORDAN, G.R., WALLIS, G.R. Geophysical Borehole Logging Handbook for Coal Exploration. Alberta (CAN), The Coal Mining Research Centre, 1982. $270 \mathrm{p}$.

OLIVEIRA, L.J. de. Avaliação do uso da pefilagem geofísica para obtenção de informações secundárias para utilização em co-estimativas de variáveis geológico-mineiras. Porto Alegre: PPGEM-EE-UFRGS, 2005. 164 p. (Dissertação de Mestrado).

Artigo recebido em 06/06/2008 e aprovado em 25/05/2009.

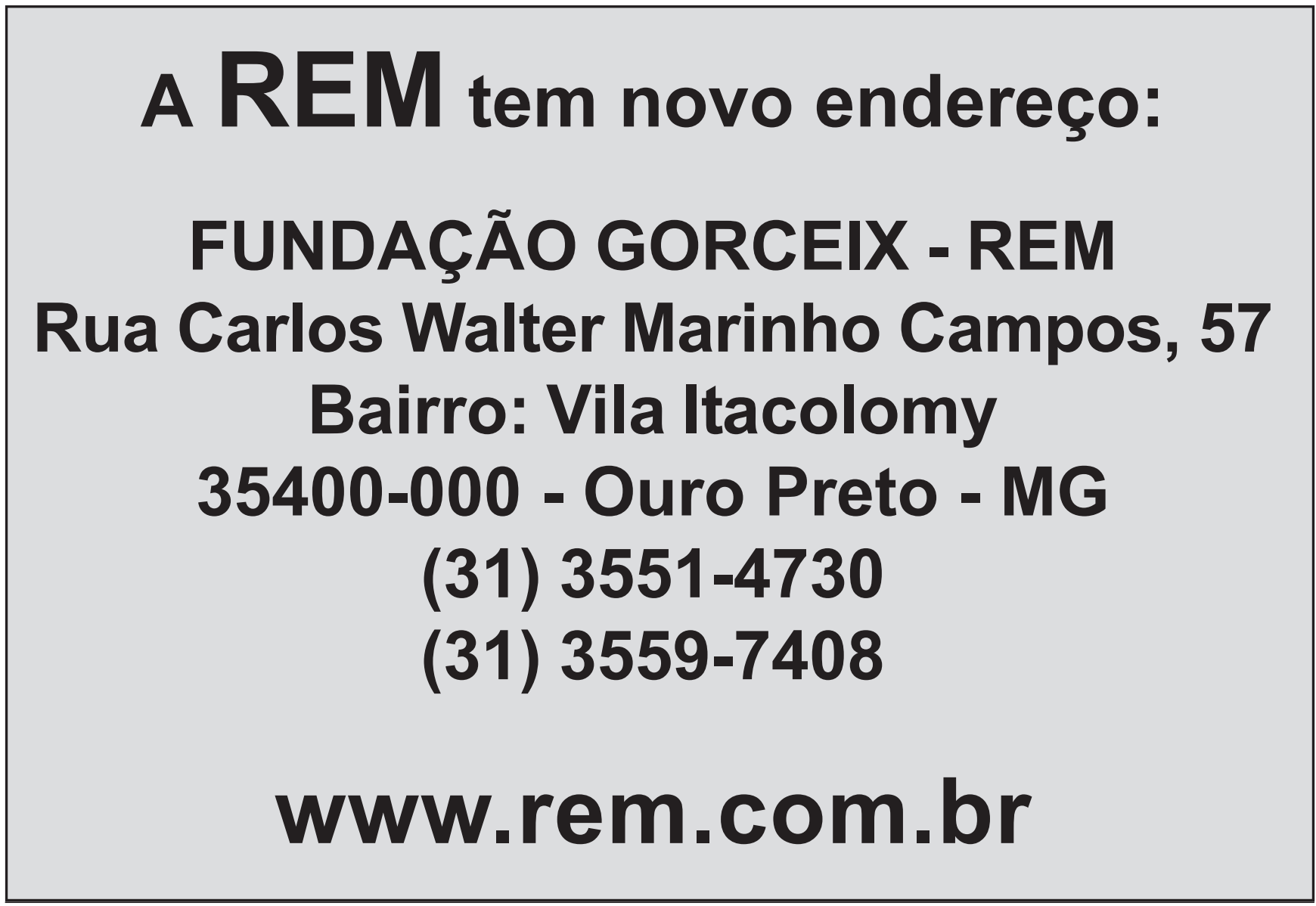

